\title{
MIMO Multiband Balanced Antenna Design for Wireless Communication
}

\author{
Assed Sami \\ Department of Electrical/Telecomm ICT \\ Islamabad affiliated with UET Peshawar
}

\begin{abstract}
In this paper the wide band antenna with broad bandwidth that can be utilized in different frequency band. Band covers from 750 to $5000 \mathrm{MHZ}$ and GSM, UMTS, Bluetooth, GPS, \& Wifi applications is examined The antenna has been design on HFSS. It is a low Profile Balanced antenna. Linear phase and constant radiation pattern with proper return loss and resonant on multiple frequencies
\end{abstract}

\section{General Terms}

Wide band balance antennas, low profile balanced antenna, unbalanced antenna, VSWR, radiation pattern, Return losses,

\section{Keywords}

Low profile, MIMO balanced antenna, VSWR, radiation pattern.

\section{INTRODUCTION}

As Technology is growing day by day. Antenna is fabricated near the ground plane, which affects the overall efficiency of the antenna. Balanced antenna technology was introduced to cop up with this problem and minimize the current in the ground plane. In this design current will only flow in the antenna elements, and minimizing the effect of the current flow on the ground plane. In this paper Wide band balanced antenna for wireless communication was designed and analyzed, also the antenna will be able to resonant on multiple frequencies.HFSS was used to measure the different aspects of the antenna i.e. return loss, current gain and radiation parameter. Deigned antenna was then fabricated on FR-4 Epoxy and the results were exacted from the network analyzer and anechoic chamber and compared it with theoretical aspects

\section{DESIGNED ANTENNA}

The designed antenna shown in figure 1(a) has a ambled rectangular patch practical on the FR-4 epoxy substrate. In balanced antenna, current distribution in ground plane is cancel minor copy of the patch is executed with is unique one

The dimensions of the single substrate are $(30 \mathrm{~mm} \times 7 \mathrm{~mm} \times$ $1.6 \mathrm{~mm})$. The ground having dimensions $(80 \times 30)$ is used as reference mobile ground. As shown in figure 1(a) \&1(b).

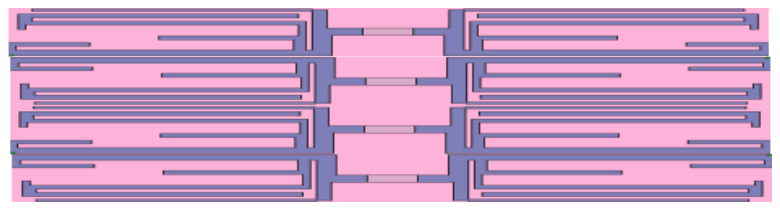

Figure 1 (a): designed balanced patch antenna

\author{
Shahzada Alamgir,Ph D \\ Associate professor ICT PTCL academy \\ Islamabad
}

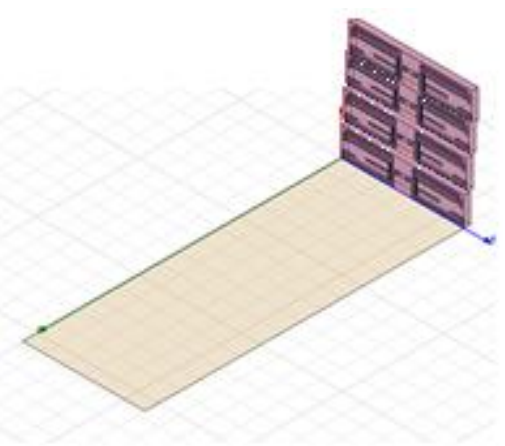

Figure 1 (b): Balanced patch antenna with ground

Probe feeding technique is used for the feeding of the antenna. Same magnitude but opposite in phase and two different individual feed line inputs are used to feed the antenna.

Antenna is able to resonant on multiple frequencies band range due to multiple paths lengths. The lower path is regulatory the lower frequency bands. The upper most paths are regulatory the higher frequency bands. The middle path is playing roll in the middle notch and the bandwidth of the antenna. You will see these prospects in results section

\section{RESULTS}

In this section, Mentioned are the simulated results of the and (a) Return loss, (b) Radiation patterns and (c) VSWR graph of the implemented design are displayed under:

\subsection{Return Loss}

In figure 2 the return loss [18] simulated in HFSS

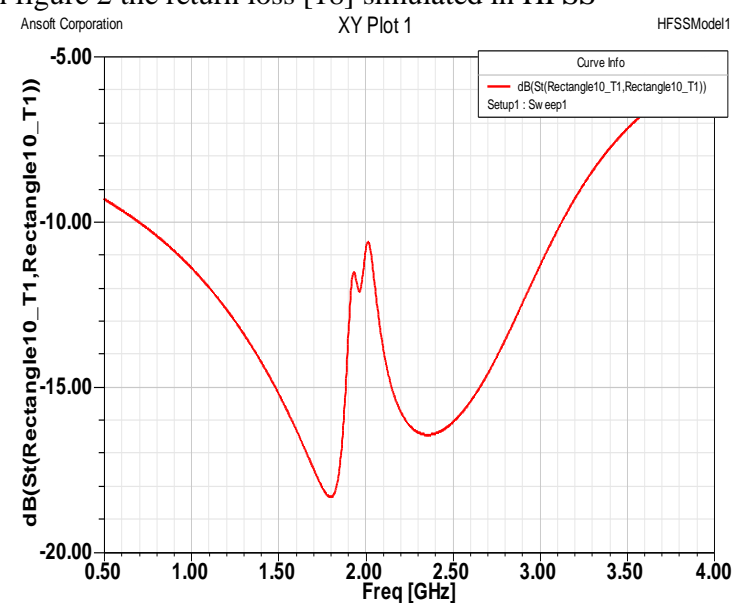

Figure 2: Return loss of proposed antenna 


\subsection{Radiation Patterns 2D}

The 2D XY, YZ, ZX radiation pattern at multiple operating frequencies are displayed in figure 3(a) to 3(e).

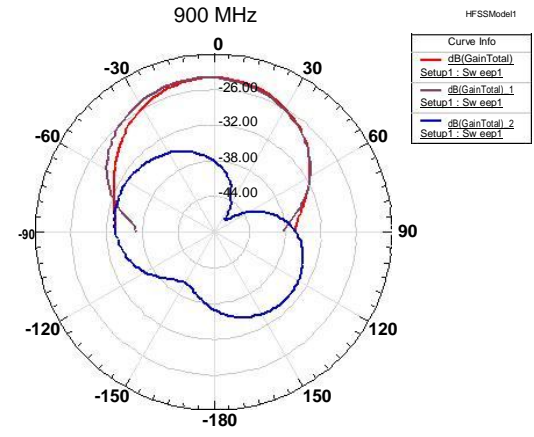

Figure 3(a): 2D Radiation pattern at $900 \mathrm{MHz}$

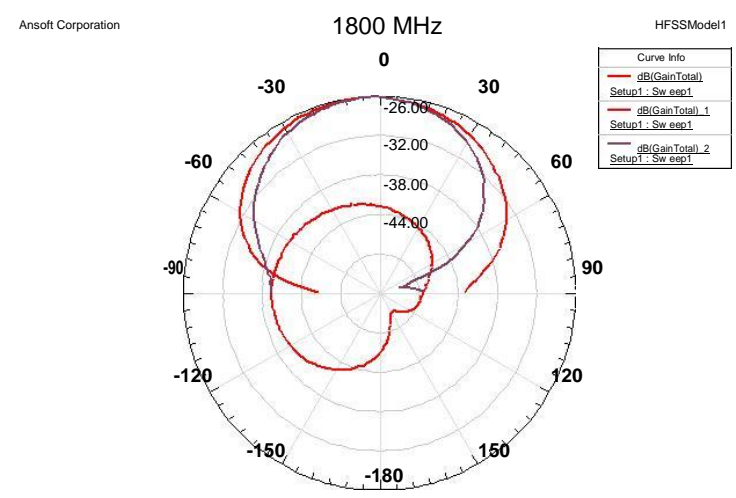

Figure 3(b): 2D Radiation pattern at $1800 \mathrm{MHz}$

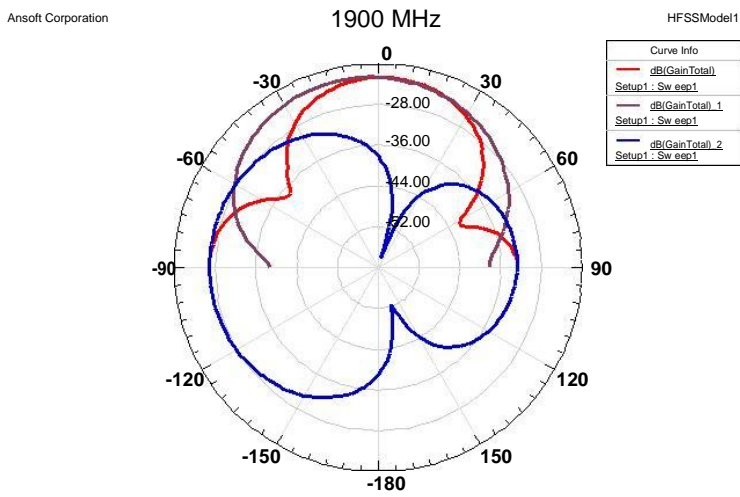

Figure 3(c): 2D Radiation pattern at $1900 \mathrm{MHz}$

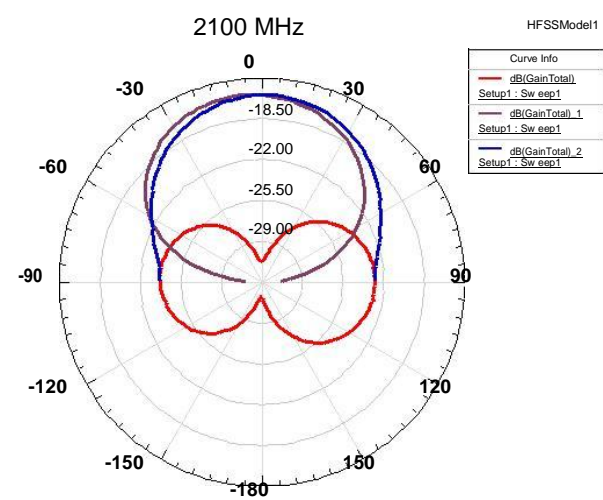

Figure 3(d): 2D Radiation pattern at $2100 \mathrm{MHz}$

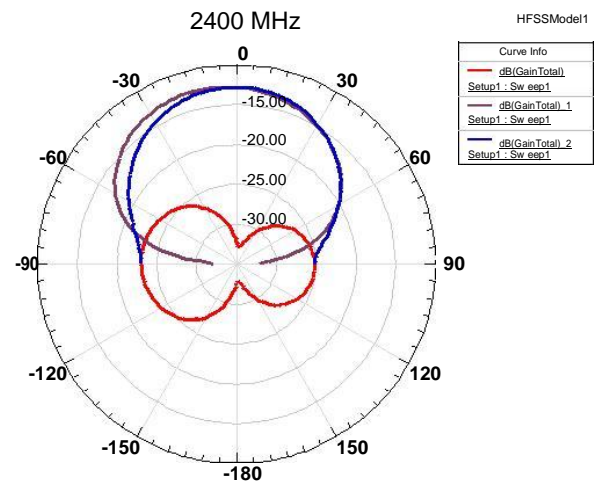

Figure 3(e): 2D Radiation pattern at $2400 \mathrm{MHz}$

\subsection{VSWR}

For low gain mobile terminal antennas $\rho \leq 2$ and $\rho \leq 3$ [16].

Preferably, in case of no transmission line mismatch.

VSWR is equal to unity

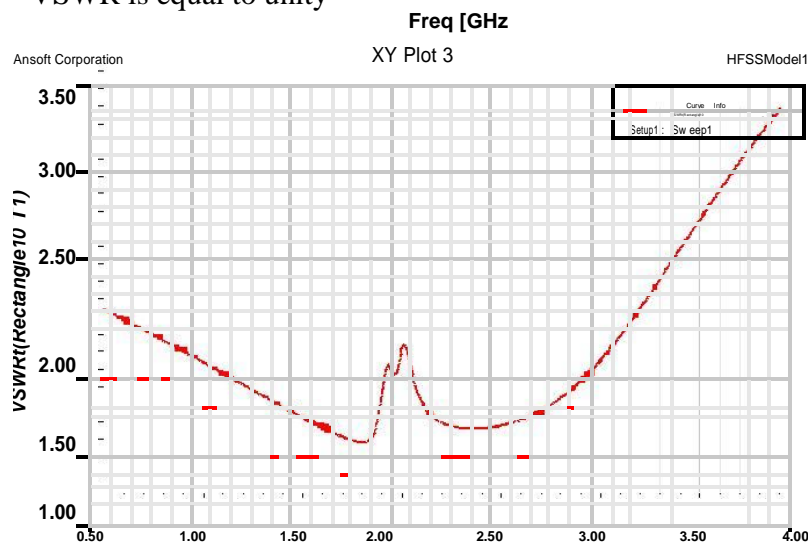

Figure 4: Showing VSWR characteristic of final antenna i.e. less than 2 for the operating region

\subsection{D Polar Plots}

The 3D polar patterns at multiple operating frequencies are shown in figure $5(\mathrm{a})$ to $5(\mathrm{~h})$.

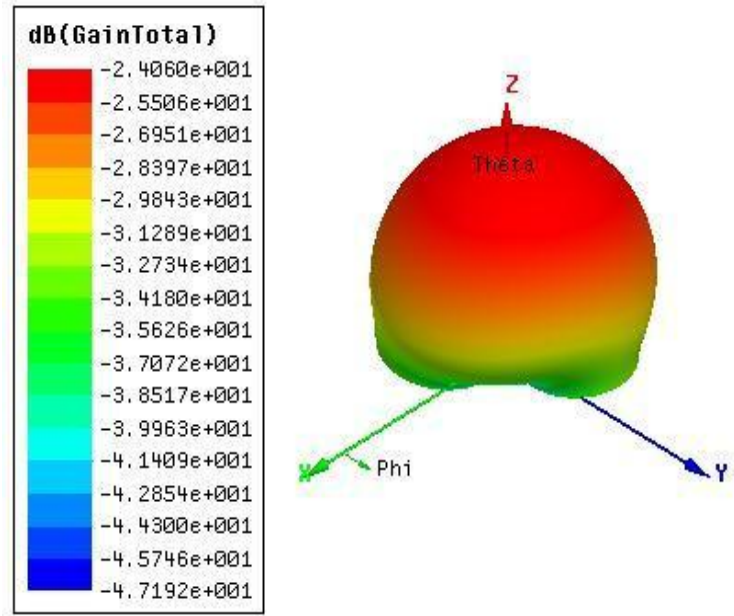

Figure 5(a): 3D polar pattern at $900 \mathrm{MHz}$ 


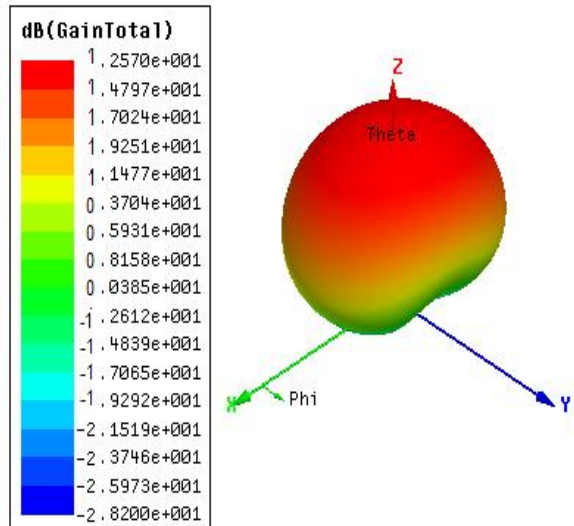

Figure 5(b): 3D polar pattern at $1800 \mathrm{MHz}$

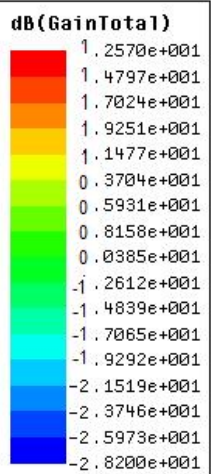

Figure 5(c): 3D polar pattern at $1900 \mathrm{MHz}$

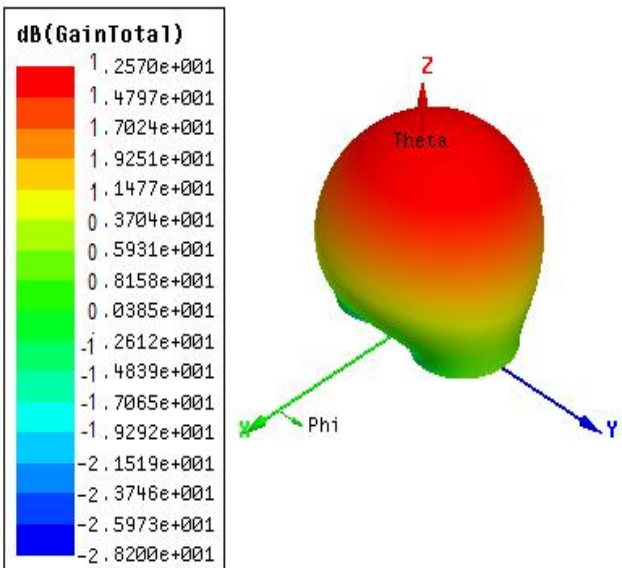

Figure 5(d): 3D polar pattern at $2100 \mathrm{MHz}$
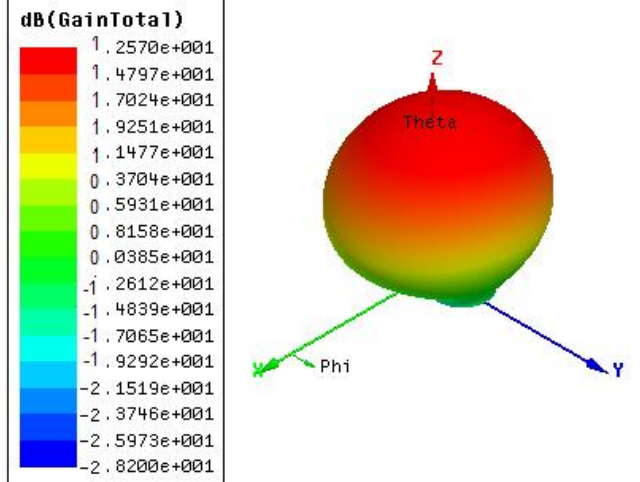

Figure 5(e): 3D polar pattern at $2400 \mathrm{MHz}$

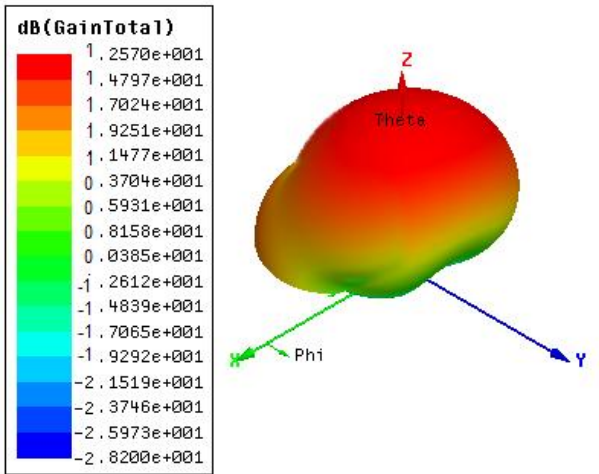

Figure 5(f): 3D polar pattern at $3000 \mathrm{MHz}$

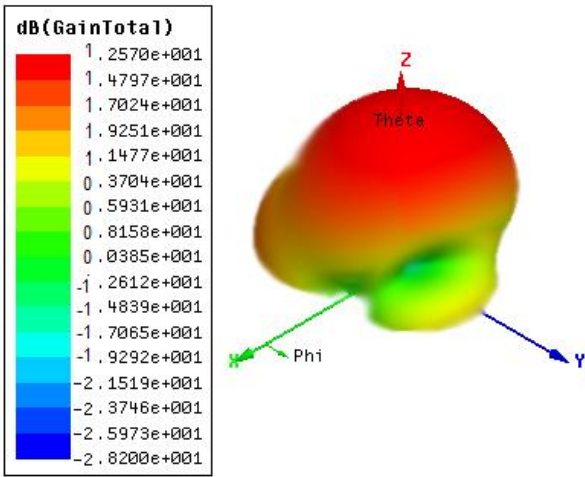

Figure 5(g): 3D polar pattern at $5000 \mathrm{MHz}$

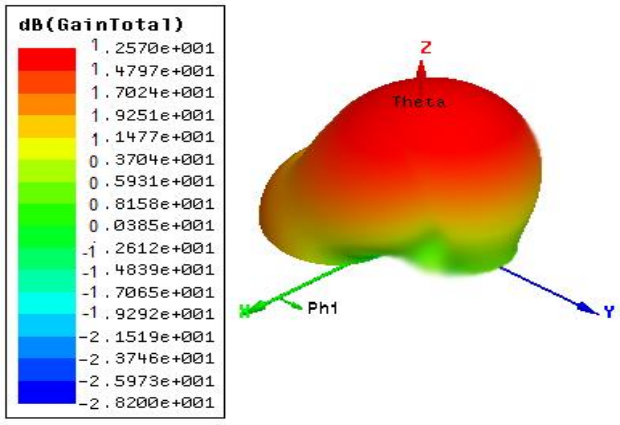

Figure 5(h): 3D polar pattern at $7000 \mathrm{MHz}$

\section{PROTO TYPE}

A prototype MIMO Balanced antenna is fabricated

In the process of fabrication, Copper layered substrate is used. For the etching the copper patch on the substrate ferric chloride id utilized.80X30mm sheet is used to ground the antenna, Mentioned in the figure 7 (a)

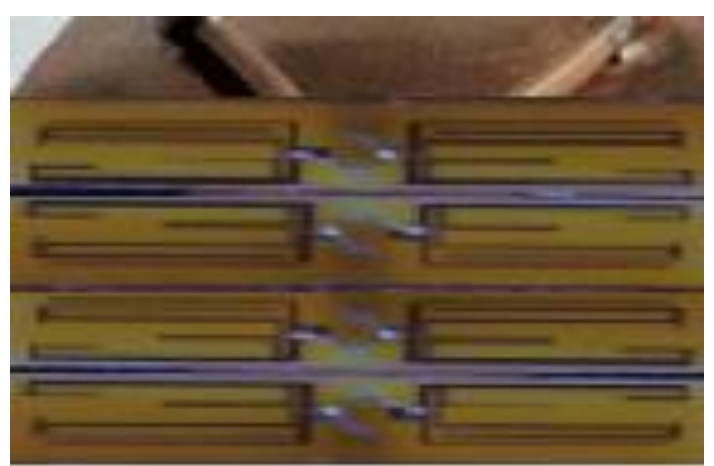

Figure 7(a): The proto type design of the antenna 
Fabricated antenna is then measured by the matlab and network analyzer, as shown in the given below figure 8 (a) and 8 (b)

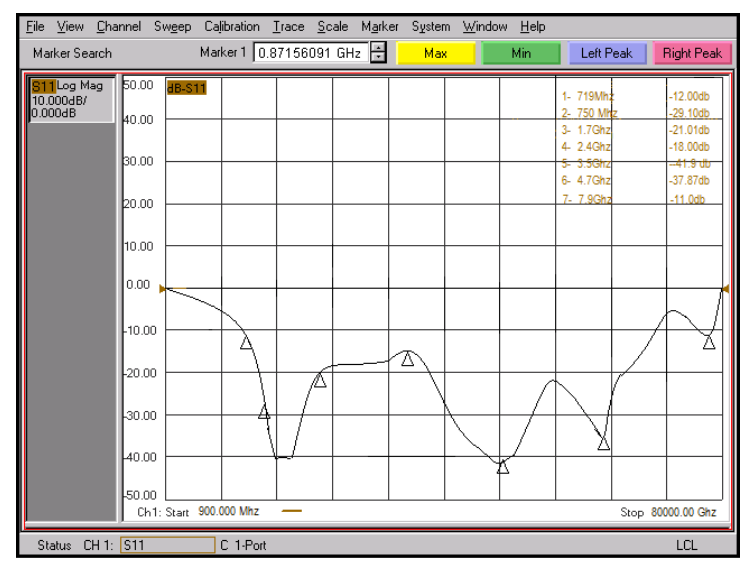

Figure 8(a): Return loss of the antenna on Network analyzer.

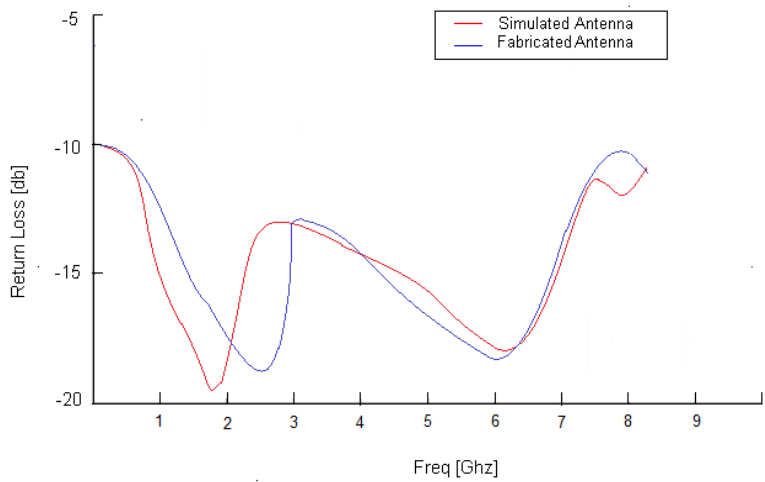

Figure 8(a): Return loss plotted on Matlab

There is difference in the fabricated and simulated antenna that can been easily seen from the figure mentioned above, as the s11 parameter [18] a bit shifted to the left side from the main reference S11 parameter of the base simulated antenna, the reason is that feeding cable are not perfectly matched, also there is the losses of SMA connectors, But still it will resonate on pre-described frequency band $[14,15]$.

\section{CONCLUSION}

This MIMO Multiband balanced antenna can be used in mobile phones, and wireless adopters (Wi-max, Wi-Fi) because of its compact size, low profile and Isolation of Ground plane Radiation Patch Antenna is very much efficient and vital in developed technology of these days, but commonly unbalanced antennas are used which normally level down the efficiency of the antenna. In this paper this is been instructed that low profile antenna can work efficiently on mobile application [12,13] working bandwidth of 750 MHZ to 3000 MHZ.

This type of antenna can able to resonant on multiple bands of frequencies of various applications and also the efficiency of the antenna be hold with effective level when it fabricated near to ground plan The problem was solved by proposing a balanced patch on the FR-4 substrate, in order to retains its efficiency and reduction of current in lumped $(\mathrm{R}, \mathrm{L} \& \mathrm{C})$ elements. Finally it is able to provide the reasonable bandwidth which is perfectly utilized for the mobile communication. [6, 10 \&11].

\section{ACKNOWLEDGEMENTS}

The authors would like to say thanks to their parents, my teachers Prof. Shahzada Alamgir, Dr. Khalil Ahmad for their prayers, care and appreciated response

\section{REFERENCES}

[1] John D. Kraus, Ronald J.marhefka, Ahmed S. khan, "Antennas for all applications, 3rd Edition.

[2] Constantine A. Balanis "Antenna Theory Analysis and Design" 3rd Edition, John Wiley \& Sons Inc, 1997

[3] K. L. Wong, "Design of Non-planar Microstrip Antennas and Transmission Lines", New York: John Wiley \& Sons, 1999

[4] E. Lee, P. S. Hall, and P. Gardner, "Dual band folded monopole/loop antenna for terrestrial communications system", Electron. Lett., vol. 36, pp. 1990-1991, Nov. 23,2000 .

[5] P. Haapala, P. Vainikainen, and P. Eratuuli, "Dual frequency helical antennas for handsets", in Proc. 1996 IEEE Vehicular Technol. Conf, pp.336-338.

[6] K.-L. Wong, G.-Y. Lee, and T.-W. Chiou, "A lowprofile planar monopole antennas for multiband operation of mobile handsets", IEEE Trans. Antennas Propag., vol. 51, no. 1, pp. 121-125, Jan. 2003.

[7] Y.-L. Kuo and K.-L. Wong, "Printed double-T monopole antenna for 2.4/5.2 GHz dual-band WLAN operations", IEEE Trans. Antennas Propag., vol. 51, no. 9, pp. 2187 2192, Sep. 2003

[8] Warren L. Stutzman, G.A.T., Antenna Theory and Design. 1981.

[9] Sato, K., Matsumoto, K. Fujimoto and K. Hirasawa, Characteristics of Planar Inverted-F antenna on a Rectangular Conducting Body. Trans. IECIE, 1988. J71B: p. 1237-1243.

[10] James, J.R. and K. Fujimoto, Mobile antenna systems handbook. 1994, Boston ; London: Artech House. xvi, $617 \mathrm{p}$.

[11] Taga T., a.K.T., Performance Analysis of a Built in Planar Inverted-F antenna for $800 \mathrm{Mhz}$ Band Portable Units. IEE JSAC, 1987. SAC 5 no. 5: p. 921-929.

[12] Kathleen L.Virga and Yahya Rahmat-Samii,"LowProfile enhanced Bandwidth PIFA for Wireless Communications Packaging" IEEE Transactions on Mcrowave Theory and Techniques, vol. 45, no. 10, pp. 1879-1888, October 1997.

[13] Terry Kin-chung Lo and Yeongming Hwang, Bandwidth Enhancement of PIFA Loaded with Very High Permittivity Material Using FDTD”, IEEE antennas and Propagation Society International Symposium, vol.2, pp.798-801, June 1998.

[14] A. Ghorbani, M. Ansarizadeh, and R. A. Abd-alhameed, "Bandwidth Limitations on Linearly Polarized Microstrip Antennas," IEEE Transactions on Antennas and Propagation, Vol. 58, No. 2, 2010, pp. 250-257.

[15] Nariman Firoozy, Mahmoud Shirazi, “ Planar InvertedF Antenna (PIFA) Design Dissection for Cellular communication Application" Journal of Electromagnetic 
Analysis and Applications, 2011, 3, 406-411, doi:10.4236/jemaa.2011.310064 Published Online October 2011.

[16] Zhou, D., Abd-Alhameed, R. A., See, C. H. and Excell, P. S.(2009) 'Design of Wideband Balanced Folded-Arms Dipole Antenna for Mobile Handsets', Electromagnetism, 29: 8, 641 - 651

[17] Valderas, D., J. Legarda, I. Gutierrez, \& J. I. Sancho. 2006. Design of UWB folded-plate monopole antennas based on TLM. IEEE Trans. Antennas Propagation. 54:1676-1687.

[18] Meys, R., \& F. Janssens. 1998. Measuring the impedance of balanced antennas by an S-parameter method. IEEE Antennas Propagation. Mag. 40:62-65.

[19] Wong, K.-L., C.-H. Wu, \& S.-W. Su. 2005. Ultra wideband square planar metal-plate monopole antenna with a trident-shaped feeding strip. IEEE Trans. Antennas Propagation. 53:1262-1269.

[20] T. Yang, W.A. Davis, and W.L. Stutzman, "FoldedNotch Dual Band Ultra-Wideband Antenna", IEEE Antennas and Propagation Society International symposium, (Washington, DC), Poster Paper 17.8, July 3-8 2005. (Paper 05-6)

[21] Seong-Youp Suh, Warren L. Stutzman, and William A. Davis, " A New Ultra wideband Printed Monopole Antenna: The Planar Inverted Cone Antenna (PICA)," IEEE transactions on Antennas and Propagation, vol. 52, no. 5, pp. 1361-1365, May 2004. (Paper 04-01)
[22] Mehdipour, A., K. M. Aghdam, and R. Faraji-Dana, "Complete dispersion analysis of Vivaldi antenna for ultra wideband applications," Progress Electromagnetics Research, Vol. 77, 85-96, 2007.

[23] Lin, S., S. Yang, and A. E. Fathy, "Development of a novel UWB vivaldi antenna array using SIW Technology," Progress In Electromagnetics Research, Vol. 90, 369-384, 2009.

[24] Behera, A. R. and A. R. Harish, "A novel printed wideband dipole antenna," IEEE Trans. Antennas Propag., Vol. 60, No. 9, 4418-4422, Sep. 2012.

[25] Cappelletti, G., D. Caratelli, R. Cicchetti, and M. Simeoni, "A low-profile printed drop-shaped dipole antenna for wide-band wireless applications," IEEE Trans. Antennas Propag.,Vol. 59, No. 10, 3526-3534, Oct. 2011.

[26] Ling, J., S.-X. Gong, B. Lu, H.-W. Yuan, W.-T. Wang, and S. Liu, "A microstrip printed dipole antenna with UC-EB ground for RCS reduction," Journal of Electromagnetic Waves and Applications, Vol. 23, Nos. 5-6, 607-616, 2009.

[27] Bourqui, J., M. Okoniewski, and E. C. Fear, "Balanced antipodal Vivaldi antenna with dielectric director for nearfield microwave imaging," IEEE Trans. Antennas Propag., Vol. 58, No. 7, 2318-2326, Jul. 2010.

[28] Ruvio, G., "UWB breast cancer detection with numerical phantom and Vivaldi antenna," Proc. of the 2011 IEEE International Conference on Ultra-wideband (ICUWB), 8-11,Bologna, Italy, Sep. 2011. 